* Acadêmico de Direito $-4^{\circ}$ ano da Universidade Estadual de Londrina. Membro do Grupo de Formação Complementar em DIDH e Mecanismos de Solução de Conflitos. Monitor das disciplinas Direito Constitucional II e Processo Civil II

E-mail: joserbaron@hotmail.com; Universidade Estadual de Londrina

** Doutor em Ciências Jurídicas pela Universidade Federal de Santa Catarina. Professor em Direito Constitucional na Universidade Estadual de Londrina. Procurador do Município de Londrina

E-mail: joao.esteves1000@gmail. com

\section{A Legitimidade do Ministério PÚBLICO PARA IMPETRAR O MANDADO DE SEGURANÇA COLETIVO NA PROTEÇÃo DOS DIREITOS DIFUSOS, COLETIVOS E INDIVIDUAIS INDISPONÍVEIS À LUZ DA LEGISLAÇÃ̃o BRASILEIRA}

PROCEDURAL PERMISSIVENESS FOR THE PUBLIC PROSECUTOR TO SUE CLASS ACTIONS IN FAVOR OF DIFFUSE, COLLECTIVE AND INDIVIDUAL NON DISPOSABLE RIGHTS ON BEHALF OF BRAZILIAN LAW

\section{José Ricardo da Silva Baron* João Luiz Martins Esteves**}

Como citar: BARON, José Ricado da Silva. ESTEVES, João Luis Martins. A legitimidade do ministério público para impetrar o mandado de segurança coletivo na proteção dos direitos difusos, coletivos e individuais indisponíveis à luz da legislação brasileira. Revista do Instituto de Direito Constitucional e Cidadania, Londrina, v. 3, n. 2, p. 136-150, jul/dez. 2018.

https://doi.org/10.48159/revistadoidcc.v3n2.baron.esteves

Resumo: A função primordial do presente estudo é apresentar a evolução histórica do mandado de segurança, os legitimados para impetrar o mandado de segurança individual e coletivo, assim como a possibilidade do Ministério Público figurar como legitimado para impetração do mandado de segurança coletivo quando envolver direito individual indisponível, coletivo ou difuso, mesmo que não seja parte constante no inciso LXX do artigo $5^{\circ}$ da Constituição Federal de 1988. Desse modo, será feita a análise por meio da conceituação e evolução do mandado de segurança na legislação brasileira, assim como de decisões judiciais sobre a possibilidade do Ministério-Público ser parte legítima no mandado de segurança coletivo.

Palavras-Chave: Ministério-Público. Mandado de Segurança Coletivo. Direito Difuso. Direito Coletivo. Legitimidade.

Abstract: The main function of this study is to present the historical evolution of the writ of mandamus, those legitimated to file the individual and collective writ of mandamus, as well as the possibility of the Public Prosecutor's Office to appear as legitimized to impetration the collective writ of mandamus when it involves individual,unavailable, collective or diffuse rights, even if it is not a constant part of item LXX of article 5 of the Federal Constitution of 1988.An analysis it will be performed through the conceptualization and evolution of the writ of 
mandamus in Brazilian legislation, as well as judicial decisions about a possibility of the Public Prosecutor's Office being a legitimate part to impetrate a collective writ of mandamus.

Keys-Words: Public Prosecutor's Office. Collective Writ of Mandamus. Diffused Right. Collective Right. Legitimacy. 


\section{INTRODUÇÃO}

O mandado de segurança, está previsto nos incisos LIX e LXX do artigo $5^{\circ}$ da Constituição da República Federativa do Brasil de 1988 e disciplinado pela Lei n ${ }^{\circ} 12.016$ de 07 de agosto de 2009 (Lei do mandado de segurança).

Sua função primordial é proteger direito líquido e certo contra autoridade pública ou representante de pessoa jurídica no exercício de função pública, não protegido por habeas corpus ou habeas data.

Dessa forma, o remédio constitucional pode ser individual ou coletivo. O mandado de segurança individual não apresenta grandes questionamentos sobre a possibilidade de cabimento e sobre os legitimados para impetrá-lo. Por sua vez, o mandado de segurança ainda é matéria divergente na doutrina e jurisprudência, sendo que de acordo com a Lei 12.016/09, o mandado de segurança coletivo é cabível para proteger direitos coletivos, individuais homogêneos e os legitimados para impetração do mandado de segurança coletivo constam no inciso LXX do artigo $5^{\circ}$ da Constituição Federal de 1988.

Porém, muito se discute sobre a possibilidade do Ministério Público ser parte legitima para impetração do writ coletivo quando versar sobre direito individual indisponível, coletivo ou difuso, mesmo não parte no rol do inciso LXX do artigo $5^{\circ}$ da Constituição.Porém, o Ministério Público apresenta, conforme estabelece o artigo 127 e 129 da Constituição Federal, a função de proteger os direitos difusos, coletivos, sociais e individuais indisponíveis.

Portanto, o presente estudo se pauta na possibilidade do Ministério Público, mesmo sem ser parte constante nos legitimados, impetrar o mandado de segurança coletivo em defesa de direito individual indisponível, coletivo ou difuso, garantindo assim, o máximo de instrumentos disponíveis para proteção da sociedade por parte do Ministério Público.

Utiliza-se do método analítico para elaboração do presente estudo, implicando na decomposição do fenômeno, em suas partes constitutivas. É uma operação mental pela que se divide a representação totalizadora de um fenômeno em suas partes.

\section{DESENVOLVIMENTO}

O mandado de segurançasurgiuno Brasil na primeira metade do século XX, sendo que o primeiro diploma legal que previu a possibilidade de existência do mandado de segurança foia Constituição de 1934.

Anteriormente, já existiam mecanismos de proteção contra eventual lesão que cidadão possa ter sofrido por parte de ato do agente público. Porém, os meios processuais disponível passaram a ser utilizados cabalmente, conforme Alessandra Mendes Spalding assevera:

[...] passaram a ser utilizados de forma descontrolada e inadequada a sua própria natureza jurídica, em razão da inexistência de um outro remédio processual capaz de suprir as necessidades vivenciadas nas relações entre 
Estado e particular então existente ${ }^{1}$

Desse modo, em 1934 a Constituição do Brasil passa a prever o mandado de segurança como instrumento eficaz no sentido de evitar e sanar o abuso de poder por parte do agente público. Desde modo, o artigo 113, $§ 33$ do referido diploma dispõe:

Dar-se-á mandado de segurança para defesa do direito, certo e incontestável, ameaçado ou violado por ato manifestadamente inconstitucional ou ilegal de qualquer autoridade. O processo será o mesmo do habeas corpus, devendo ser sempre ouvida a pessoa de direito público interessada. O mandado não prejudica as ações petitórias competentes ${ }^{2}$

Há uma discussão doutrinária a respeito da criação do mandado de segurança. Alguns lecionadores defendem se tratar de uma criação brasileira, por sua vez, outros juristas afirmam se tratar de uma derivação do instrumento mexicano "juicios de amparo" e do writ dos Estados Unidos da América ${ }^{3}$.

A constituição de 1937 se omitiu quanto a possibilidade de mandado de segurança, isso levou a edição do Decreto-lei n ${ }^{\circ} 6$ de 16 de novembro de 1937. Porém, a utilização do mandado de segurança não poderia ser contra atos do Presidente da República, Governadores, Interventores e Ministros.

Após o fim da era Vargas, a Constituição de 1946 passa a prever o mandado de segurança contra qualquer autoridade pública. Em 31 de dezembro de 1951 é editada a Lei 1.531 que passou a regulamentar o mandado de segurança. Tal lei foi recepcionada pela Constituição de 1967 e pela Constituição de 1988, até o advento da Lei 12.016 de 2009.

O mandado de segurança é um dos remédios constitucionais presentes no rol do artigo $5^{\circ}$ da Constituição da República Federativa do Brasil de 1988 e disciplinado pela Lei n ${ }^{\circ} 12.016$ de 07 de agosto de 2009. Conforme leciona José Antônio da Silva, "são meios postos à disposição dos indivíduos e cidadãos para provocar a intervenção das autoridades competentes, visando sanar, corrigir, ilegalidade e abuso de poder em prejuizo de direitos e interesses individuais "4(SILVA, 1996).

Além da previsão do mandado de segurança individual no artigo $5^{\circ}$, inciso LXIX, o referido dispositivo legal também prevê o mandado de segurança coletivo (inciso LXX).

Preconiza o artigo $5^{\circ}$ inciso LXIX que:

Conceder-se-á mandado de segurança para proteger direito líquido e certo, não amparado por habeas corpus ou habeas data, quando o responsável pela ilegalidade for autoridade pública ou agente de pessoa jurídica no exercício das

1 SPALDING, Alessandra Mendes. A Legitimidade Ativa na Ação Popular na Ação Civil Pública e no Mandado de Segurança Coletivo. Londrina. 2003. Dissertação (Mestrado em Direito Negocial) - Universidade Estadual de Londrina, Londrina p. 156.

2 BRASIL, Constituição da República dos Estados Unidos do Brasil (De 16 de julho de 1934). Disponível em:<http://www.planalto.gov.br/ccivil_03/constituicao/constituicao34.htm>Acesso em 10 de agosto de 2017.

3 SPALDING, Op. Cit, p. 113.

4 SILVA, José Afonso da. Curso de Direito Constitucional Positivo. 11º ed. São Paulo: Malheiros. 1996. 
atribuições do poder público; ${ }^{5}$

Desse modo, é possível constatar que o mandado de segurança conforme Hely Lopes Meirelles:

É o meio constitucional posto à disposição de toda pessoa física ou jurídica, órgão com capacidade processual, ou universalidade reconhecida por lei, para a proteção de direito individual ou coletivo, líquido e certo $[\ldots]^{6}$

E o direito líquido e certo no inciso é definido por Ives Gandra da Silva Martins como:

[...] o direito lesado ou ameaçado é um direito passível de ser demonstrado cabalmente, por prova documental perante o Juiz. Ou seja, os fatos dos quais decorre o direito podem ser de plano demonstrados ao juiz, que deve, então, conceder provimento apto a protegê-lo da arbitrariedade perpetrada ou em vias de o ser, por agente público?

Com relação ao mandado de segurança coletivo, o inciso LXX assevera:

O mandado de segurança coletivo pode ser impetrado por: a) partido político com representação no Congresso Nacional; b) organização sindical, entidade de classe ou associação legalmente constituída e em funcionamento há pelo menos um ano, em defesa de seus membros ou associados ${ }^{8}$

Assim sendo, o artigo $5^{\circ}$ inciso LXX da Constituição Federal de 1988 informa os legitimados, porém, cabe ressaltar os direitos protegidos pelo mandado de segurança coletivo. Tais direitos constam na Lei 12.016/09 que em seu artigo 21 classifica:

Art. $21[\ldots]$

Parágrafo único: Os direitos protegidos pelo mandado de segurança coletivo podem ser:

I - coletivos, assim entendido, para efeito desta Lei, ou transindividuais, de natureza indivisível, de que seja titular grupo ou categoria de pessoas ligadas entre si ou com a parte contrária por uma relação jurídica básica;

II - individuais homogêneos, assim entendidos, para efeito desta Lei, os decorrentes de origem comum e da atividade ou situação especifica da totalidade ou de parte dos associados ou membros do impetrante. ${ }^{9}$

É mister destacar que o mandado de segurança apresenta requisitos materiais e formais para a sua perfeita existência, sendo que os requisitos para impetração devem ser todos atendimentos, sob o risco de não haver o julgamento do mérito.

5 BRASIL, Constituição da República Federativa do Brasil: texto promulgado em 5 de outubro de 1988, com as alterações adotadas pelas Emendas constitucionais nº 1/1992 a 77/201, 41 ed. - Brasília: Câmara dos Deputados, Edições Câmara, 2014.

6 MEIRELLES, Hely Lopes. Mandado de Segurança. 29 ed. São Paulo: Malheiros, 2006, p. 21-22

7 MARTINS, Ives Gandra da Silva. Conheça a Constituição:Comentários à Constituição Brasileira, volume 1. Barueri-SP: Manole, 2005.

8 BRASIL, Op. Cit. p. 11

9 BRASIL, Lei 12.016 de 07 de agosto de 2009. Disciplina o mandado de segurança individual e coletivo. Brasília, DF. 2009. 
Já decidiu o Supremo Tribunal Federal que os princípios que regem o mandado de segurança individual também guiam o mandado de segurança coletivo:

\begin{abstract}
"MANDADO DE SEGURANÇA COLETIVO - DECRETO N. 646/1992 DO PRESIDENTE DA REPÚBLICA - INVESTIDURA NAS FUNÇÕES DE DESPACHANTE ADUANEIRO E DE AJUDANTE DE DESPACHANTE ADUANEIRO - IMPETRAÇÃO CONTRA ATO EM TESE - INADMISSIBILIDADE - INCIDÊNCIA DA SÚMULA N. 266 DO STF - MANDADO DE SEGURANÇA NÃO CONHECIDO. Os princípios básicos que regem o mandado de segurança individual informam e condicionam, no plano jurídico-processual, a utilização do writ mandamental coletivo [...]" (STF, RE n. 171.203, Rel. Min. Celso de Mello, Primeira Turma, j. em 7.2.1995, DJ de 18 ago. 1995, p. 24945, Ement. Vol. 01796-13, p. 02651).
\end{abstract}

Desse modo, conforme decisão transcrita, é cristalino a existência de semelhanças entre o mandado de segurança individual e o coletivo, fazendo com que seja possível até mesmo a compatibilidade de princípios.

\title{
2.1 Legitimidade
}

\subsubsection{Mandado de Segurança Individual}

A legitimidade para impetração do mandado de segurança individual não apresenta grandes questionamentos e discussões por parte da doutrina e jurisprudência, sendo de fácil conceituação e percepção. Conforme José Afonso da Silva, os legitimados são os: titulares de direito líquido e certo, lesado ou ameaçado de lesão, por ato ou omissão de autoridade pública ou agente de pessoa jurídica no exercício de atribuições do Poder Público ${ }^{10}$

Estabelece o inciso LXIX do artigo $5^{\circ}$ da Constituição de 1998:

Conceder-se-á mandado de segurança para proteger direito líquido e certo, não amparado por habeas corpus ou habeas data, quando o responsável pela ilegalidade for autoridade pública ou agente de pessoa jurídica no exercício das atribuições do poder público; ${ }^{11}$

Observa-se que o legitimado para impetração do mandado de segurança individual é aquele que sofre a ilegalidade por parte da autoridade pública ou agente de pessoa jurídica no exercício das atribuições do poder público e que essa ilegalidade não seja amparada por habeas corpus ou habeas data e se trate de direito líquido e certo.

Ademais, o artigo $1^{\circ}$ da Lei 12.016 de 2009 apresenta de forma complementar a possibilidade de aplicação do mandado de segurança e também de forma mais precisa os legitimados para impetração:

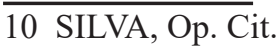

Art. 1ํCㅡㄹ Conceder-se-á mandado de segurança para proteger direito líquido e certo,

11 BRASIL, Op. Cit.p.11 
não amparado por habeas corpus ou habeas data, sempre que, ilegalmente ou com abuso de poder, qualquer pessoa física ou jurídica sofrer violação ou houver justo receio de sofrê-la por parte de autoridade, seja de que categoria for e sejam quais forem as funções que exerça. ${ }^{12}$

Observa-se que pessoa jurídica também consta como possível tutelada e legitimada para impetrar o mandado de segurança, além de haver a possibilidade quando existir o perigo de sofrer violação ilegal ou abusiva, não sendo necessário ocorrer o evento violência abusiva ou ilegal.

Por sua vez, o artigo $3^{\circ}$ da Lei 12.016 prevê a legitimidade de terceiro para impetrar mandado de segurança quando o portador do direito originário não fizer:

Art. 3ํㅡ $\mathrm{O}$ titular de direito líquido e certo decorrente de direito, em condições idênticas, de terceiro poderá impetrar mandado de segurança a favor do direito originário, se o seu titular não o fizer, no prazo de 30 (trinta) dias, quando notificado judicialmente ${ }^{13}$.

Desse modo, é possível constatar que o artigo $3^{\circ}$ possibilita ao agente que tem direito derivado, agir na ausência de ação por parte do que detêm o direito originário. $\mathrm{O}$ mandado de segurança, instrumento existente para proteção de direito líquido e certo, permite que, na inércia daquele que é diretamente afetado pela ilegalidade ou abuso de poder, passe a pleitear em juízo aquele que tem de forma derivada o direito que se mostra em risco. Sendo assim, o terceiro que passa a pleitear em juízo age como substituto processual

Porém, existem requisitos para a configuração da hipótese. Tais requisitos são o direito do substituto deve decorrer ou derivar do direito do originário; ambos devem se apresentar como direitos líquidos e certos; diante do ato coator, o titular do direito originário se mantém inerte, sendo necessário que tenha sido notificado para agir, em prazo razoável.

Além disso, também se mostra importante a possibilidade de impetração de mandado de segurança por terceiro interessado em processo judicial. Decisão do Superior Tribunal de Justiça de novembro de 2015 afirma a possibilidade de utilização de mandado de segurança como terceiro interessado em processo judicial

RECURSO ORDINÁRIO EM MANDADO DE SEGURANÇA.ATO JUDICIAL. EXCEPCIONALIDADE CONFIGURADA. MANIFESTA ILEGALIDADE. TERCEIRO PREJUDICADO (SÚMULA N. 202/STJ). RECURSO PROVIDO. SEGURANÇA CONCEDIDA. 1. Fora das circunstâncias normais, a doutrina e a jurisprudência majoritárias admitem o manejo de mandado se segurança contra ato judicial, ao menos nas seguintes hipóteses excepcionais: a) decisão judicial manifestamente ilegal ou teratológica; b) decisão judicial contra a qual não caiba recurso; c) para imprimir efeito suspensivo a recurso desprovido de tal atributo; e d) quando impetrado por terceiro prejudicado por decisão judicial. 2. Na espécie, o ato judicial apontado como coator mostra-se teratológico, pois, ausente de fundamentação jurídica, deferiu, contra terceiro estranho à lide, sem o mínimo

12 BRASIL, Lei ${ }^{\circ} 12.016$ de 07 de agosto de 2009. Disponível em:

<http://www.planalto.gov.br/ccivil_03/_ato2007-2010/2009/lei/112016.htm> Acesso em: 29 de janeiro de 2017

13 BRASIL, Op. Cit. 
de contraditório, pedido de restituição de valores sem sequer cogitar de ouvir a instituição financeira impetrante acerca da origem e titularidade dos ativos financeiros reclamados, contrariando os princípios do contraditório, da ampla defesa e da motivação, colorários do Devido Processo Legal. 3. Incidência da Súmula n. 202/STJ: "A impetração de segurança por terceiro, contra ato judicial, não se condiciona a interposição de recurso". 4. Recurso provido para conceder a segurança, cassando-se o ato apontado como coator. ${ }^{14}$

O ensejador da possibilidade de impetração do mandado de segurança é a violação de direito líquido e certo. Ou seja, qualquer um que afetado seja pela violação de direito líquido e certo, abuso de autoridade ou de poder pode impetrar o remédio constitucional, mesmo que não se mostre como portadordo direito originário

\subsubsection{Mandado de Segurança Coletivo}

Entretanto, ao contrário do mandado de segurança individual, muito se discute com relação aos legitimados para impetrar o mandado de segurança coletivo. O rol de legitimados para o mandado de segurança coletivo deriva da interpretação da lei. De acordo com o artigo 23 da Lei n. 12.016 estão autorizados a impetrar mandado de segurança coletivo:

- Partido político com representação no Congresso Nacional;

- Organização sindical;

- Entidade de classe;

- Associação

Em tese e por meio de uma análise sumária, os elencados acima seriam os únicos autorizado a realizar a impetração de mandado de segurança.

No que diz respeito ao partido político com representação no Congresso Nacional, existeo questionamento se a possibilidade de impetração é apenas favorecendo seus filiados ou atingido toda a sociedade.

Eduardo Arruada Alvim leciona que existe uma clara tendência no sentido de ampliar a interpretação do requisito pertinência temática dos partidos políticos impetrarem o mandado de segurança ${ }^{15}$

"Para impetração do mandamus, é essencial que estejam em pauta interesses dos
membros ou associados, a teor da alínea $b$ do inciso LXX do art. $5^{\circ}$ da CF.
Tratando-se, a seu turno, da hipótese prevista na alínea $a$, o requisito da
pertinência temática haverá de ser compreendido de modo mais amplo do que
aquele previsto na alínea $b$, pois não se vislumbra a exigência de impetração de
mandado de segurança coletivo "em defesa dos interesses de seus membros
ou associados". Em casos tais, estará legitimado o partido político para a

14 RMS 49.020/SP, Rel. Ministro RAUL ARAÚJO, QUARTA TURMA, julgado em 10/11/2015, DJe 26/11/2015 15 ALVIM, Eduardo Arruda. Direito Processual Civil. $2^{\mathrm{a}}$ Edição. São Paulo: Editora Revista dos Tribunais, 2008. (p. 661-663) 
impetração de mandado de segurança coletivo, desde que os objetivos colimados por essa via digam respeito às finalidades dos partidos políticos."

Com relação ao que aos elencados pelo inciso LXX alínea " $a$ ” $e$ " $b$ " do artigo $5^{\circ}$, muito se discute por parte da doutrina e jurisprudência sobre a possibilidade de se tratar de um rol taxativo ou meramente exemplificativo.

\subsubsection{Legitimidade do Ministério Público para impetrar o mandado de segurança coletivo}

A pretensão principal deste estudo é sobre a possibilidade do Ministério Público, conforme suas prerrogativas, ser um dos legitimados para impetrar mandado de segurança coletivo.

Com o escopo de construir o cenário que legítima a possibilidade do Ministério Público impetrar o wirt, deve-se levar em consideração o que o artigo 127 da Constituição Federal de 1988 preconiza:

Art. 127. O Ministério Público é instituição permanente, essencial à função jurisdicional do Estado, incumbindo-lhe a defesa da ordem jurídica, do regime democrático e dos interesses sociais e individuais indisponíveis. ${ }^{16}$

Como demonstrado, o Ministério Público possui prerrogativas para o exercício de suas funções.Ademais, o artigo 129 da Constituição Federal, que consagra as funções do Ministério Público, também constitui instrumento essencial para caracterização da possibilidade de implantação de mandado de segurança por parte da instituição.

Leciona Navarro Ribeiro Dantas que:

Então ele pode utiliza-se do writ previsto no inciso LXIX do art. $5^{\circ}$ da Constituição, embora não esteja entre as entidades autorizadas, pelo inciso LXX do mesmo dispositivo, a faze-la a título de tutela coletiva, porquanto, se esse último inciso não traz um disposição de direito material, mas apenas de direito processual, a autorização processual para tanto, quanto ao Parquet, a Constituição a concedeu em local próprio, isto é, nas normas que definem o Ministério Público e suas atribuições $^{17}$

Ainda assim, existe discussão sobre o Ministério Público, mesmo que com relação aos direitos indisponíveis, esteja legitimado para impetrar o mandado de segurança coletivo.

Em julgado da $8^{\circ}$ Câmara Cível do Tribunal de Justiça do Rio Grande do Sul de 28 de agosto de 2012 afirma se tratar de rol taxativo o inciso LXX do artigo $5^{\circ}$ da Constituição Federal:

\footnotetext{
MANDADO DE SEGURANÇA COLETIVO. ESTATUTO DA CRIANÇA E DO ADOLESCENTE. TERMO DE AJUSTAMENTO DE CONDUTA FIRMADO ENTRE MINISTÉRIO PÚBLICO E MUNICÍPIO DE PALMEIRA DAS MISSÕES, REGULANDO O ACESSO DE PÚBLICO INFANTIL E ADOLESCENTE A FESTIVAL. ILEGITIMIDADE DA DEFENSORIA
} 16 BRASIL, Op. cit. p. 42.

17 DANTAS, Marcelo Navarro Ribeiro, Mandado de Segurança Coletivo: legitimação ativa. São Paulo: Saraiva, 2000. 
PÚBLICA. A Defensoria Pública não detém legitimidade para impetrar mandado de segurança coletivo, não se enquadrando no rol taxativo dos artigos $5^{\circ}$, LXX, da CF e 21 da Lei 12.016/2009. MANDADO DE SEGURANÇA EXTINTO, SEM RESOLUÇÃO DE MÉRITO, POR MAIORIA. (Mandado de Segurança Coletivo No 70049089212 , Oitava Câmara Cível) ${ }^{18}$

A despeito de são ser clara referência ao Ministério Público, o julgado afirma a taxatividade do instrumento legal que leciona os legitimados para impetrar o mandado de segurança coletivo.

Por sua vez, em julgado da $5^{\text {a }}$ Câmara Cível do Tribunal de Justiça do Rio de Janeiro confere legitimidade ao Ministério Público para impetrar o mandado de segurança coletivo, porém, desde que seja baseado em direito difuso, coletivo ou relação de consumo. Não sendo possível a impetração quando se tratar de grupo delimitado e pessoas identificáveis e com interesses divisíveis:

MANDADO DE SEGURANÇA COLETIVO. MINISTÉRIO PÚBLICO. LEGITIMIDADE. TRIBUTO. DIREITO INDIVIDUAL HOMOGÊNEO. 1$\mathrm{O}$ direito à desconstituição do crédito tributário relativo à taxas específicas, na medida em que se refere a um grupo delimitado de pessoas identificáveis e com interesses divisíveis, caracteriza-se apenas como individual homogêneo. 2Nesse âmbito, sem qualquer caráter difuso ou coletivo nesses interesses, ou relação de consumo, o Ministério Público carece de legitimidade para impetrar mandado de segurança coletivo para tutelá-los. ${ }^{19}$ Grifo nosso

A decisão ora transcrita assegura a legitimidade do Ministério Público impetrar o mandado de segurança coletivo. O julgado denega a possibilidade do Ministério Público como parte em razão do caso concreto se tratar de direito divisível e sem caráter difuso ou coletivo.

Por sua vez, julgamento do Superior Tribunal de Justiça (REsp 806304 Rs 2005/02124091) confere legitimidade para o Ministério Público na impetração do mandado de segurança coletivo

PROCESSUAL CIVIL. ADMINISTRATIVO. AÇÃO CIVIL PÚBLICA. SERVIÇO DE TELEFONIA CELULAR PRÉ-PAGO. CRÉDITOS ADQUIRIDOS MEDIANTE CARTÕES PRÉ-PAGOS. FIXAÇÃO DE PRAZO PARA UTILIZAÇÃO. DIREITO CONSUMERISTA. INTERESSES INDIVIDUAIS HOMOGÊNEOS. LEGITIMIDADE ATIVA DO MINISTÉRIO PÚBLICO. ARTS. 81 E 82, DO CÓDIGO DE DEFESA DO CONSUMIDOR. ART. 129, III, DA CF. LEI COMPLEMENTAR N. ${ }^{\circ}$ 75/93. DIVERGÊNCIA JURISPRUDENCIAL NÃO DEMONSTRADA.

$[\ldots]$

8. O Ministério Público ostenta legitimidade para a propositura de Ação Civil Pública em defesa de direitos transindividuais, como soem ser os direitos dos consumidores do serviço de telefonia celular pré-pago, ante a ratio essendi do art. 129, III, da Constituição Federal, arts. 81 e 82, do Código de Defesa do Consumidor e art. $1^{\circ}$, da Lei 7.347/85. Precedentes do STF (AGR no RE 424.048/

\footnotetext{
18 TJ-RS - MS: 70049089212 RS, Relator: Ricardo Moreira Lins Pastl, Data de Julgamento: 23/08/2012, Oitava Câmara Cível, Data de Publicação: Diário da Justiça do dia 28/08/2012.

19 TJ-RJ - APL: 00393071720048190001 RIO DE JANEIRO CAPITAL 11 VARA FAZ PUBLICA, Relator: MILTON FERNANDES DE SOUZA, Data de Julgamento: 20/06/2006, QUINTA CÂMARA CÍVEL, Data de Publicação: 26/06/2006
} 
SC, DJ de 25/11/2005) e S.T.J (REsp. 799.669/RJ, DJ 18.02.2008; REsp. 684712/

DF, DJ 23.11.2006 e AgRg no Resp. 633.470/CE, DJ de 19/12/2005).

9. In casu, a pretensão veiculada na Ação Civil Pública ab origine, qual seja, o reconhecimento da ilegalidade do item 4.6 (e subitens 4.6.1 e 4.6.1.1) da Norma 03/98 da ANATEL, notadamente no que pertine à restrição de prazo de validade de 90 dias para a utilização de créditos, adquiridos mediante cartões pré-pagos, imposta aos consumidores/usuários do serviço de telefonia celular pré-pago, bem como a condenação das empresas demandadas à reativação do serviço aos usuários que, em razão da não reinserção dos créditos remanescentes após o escoamento do lapso temporal in foco, sofreram interrupção na prestação do mencionado serviço, revela hipótese de interesse nitidamente coletivo e por isso apto à legitimação do Parquet

10. A nova ordem constitucional erigiu um autêntico 'concurso de ações' entre os instrumentos de tutela dos interesses transindividuais e, a fortiori, legitimou o Ministério Público para o manejo dos mesmos.

11. O novel art. 129, III, da Constituição Federal habilitou o Ministério Público à promoção de qualquer espécie de ação na defesa de direitos difusos e coletivos não se limitando à ação de reparação de danos.

12. Hodiernamente, após a constatação da importância e dos inconvenientes da legitimação isolada do cidadão, não há mais lugar para o veto da legitimatio ad causam do MP para a Ação Popular, a Ação Civil Pública ou o Mandado de Segurança coletivo.

13. Em consequência, legitima-se o Parquet a toda e qualquer demanda que vise à defesa dos interesses difusos e coletivos, sob o ângulo material ou imaterial.

14. Deveras, o Ministério Público está legitimado a defender os interesses transindividuais, quais sejam os difusos, os coletivos e os individuais homogêneos.

15. Nas ações que versam interesses individuais homogêneos, esses participam da ideologia das ações difusas, como sói ser a ação civil pública. A despersonalização desses interesses está na medida em que o Ministério Público não veicula pretensão pertencente a quem quer que seja individualmente, mas pretensão de natureza genérica, que, por via de prejudicialidade, resta por influir nas esferas individuais.

16. A assertiva decorre do fato de que a ação não se dirige a interesses individuais, mas a coisa julgada in utilibus poder ser aproveitada pelo titular do direito individual homogêneo se não tiver promovido ação própria.

17. A ação civil pública, na sua essência, versa interesses individuais homogêneos e não pode ser caracterizada como uma ação gravitante em torno de direitos disponíveis. O simples fato de o interesse ser supra individual, por si só já o torna indisponível, o que basta para legitimar o Ministério Público para a propositura dessas ações.

18. A admissão do Recurso Especial pela alínea c exige a demonstração do dissídio na forma prevista pelo RISTJ, com a demonstração das circunstâncias que assemelham os casos confrontados, não bastando, para tanto, a simples transcrição das ementas dos paradigmas.

19. Recurso Especial interposto pelo Ministério Público Federal (fls.1398/1409) e recursos adesivos apresentados por BCP S/A - INCORPORADORA DA TELET S/A (1537/1549) e TIM CELULAR S.A (fls. 1558/1571) desprovidos ${ }^{20}$ Grifei 
Observa-se que conforme item 10 a 15, a decisão do Superior Tribunal de Justiça considera assertiva a possibilidade do Ministério Público ser legitimado a impetrar mandado de segurança, porém, para os direitos difusos e coletivos.

Desse modo, se faz necessário conceituar quais são direitos difusos e coletivos. A classificação de direitos coletivos pode ser encontrada no artigo 81 do Código de Defesa do Consumidor, que assevera:

Art. 81. A defesa dos interesses e direitos dos consumidores e das vítimas poderá ser exercida em juízo individualmente, ou a título coletivo.

Parágrafo único. A defesa coletiva será exercida quando se tratar de:

I - interesses ou direitos difusos, assim entendidos, para efeitos deste código, os transindividuais, de natureza indivisível, de que sejam titulares pessoas indeterminadas e ligadas por circunstâncias de fato;

II - interesses ou direitos coletivos, assim entendidos, para efeitos deste código, os transindividuais, de natureza indivisível de que seja titular grupo, categoria ou classe de pessoas ligadas entre si ou com a parte contrária por uma relação jurídica base;

III - interesses ou direitos individuais homogêneos, assim entendidos os decorrentes de origem comum. ${ }^{21}$

No sentido lato se entende direito difuso o que não é possível determinar quais são os sujeitos titulares. Apenas apresentam como semelhança a ligação por circunstância de fato e também a indivisibilidade.

Por outro lado, os direitos coletivos, conforme conceituação do Tribunal de Justiça do Distrito Federal e dos Territórios referem-se aos:

[...]direitos de natureza indivisível de que seja titular grupo, categoria ou classe de pessoas ligadas entre si por uma relação jurídica. Os titulares do direito, embora tratados coletivamente, são determináveis ou passíveis de identificação, pois possuem vínculo jurídico. Como exemplo, há os direitos de determinadas categorias sindicais que podem, inclusive, agir por meio de seus sindicatos. ${ }^{22}$

Percebe-se que os direitos difusos e coletivos envolvem em sua grande maioria mais de um agente e que são ligados por determinada relação jurídica. O primeiro não possibilita a precisão dos indivíduos, por sua vez, o segundo possibilita, entretanto, a titularidade envolve mais de uma agente.

Cabe ressaltar o artigo 129, inciso III da Constituição Federal:

Art. 129. São funções institucionais do Ministério Público:

$[\ldots]$

III - promover o inquérito civil e a ação civil pública, para a proteção do patrimônio público e social, do meio ambiente e de outros interesses difusos e coletivos ${ }^{23}$

21 BRASIL. Código de Defesa do Consumidor (1990). In: ANGHER, Anne Joyce. VadeMecumAcadêmico de Direito RIDEEL. 18. ed. São Paulo: RIDEEL, 2014, p. 558.

22 TRIBUNAL DE JUSTIÇA DO DISTRITO FEDERAL E DOS TERRITÓRIOS. Direito Coletivo. Disponível em: $<$ http://www.tjdft.jus.br/acesso-rapido/informacoes/vocabulario-juridico/entendendo-o-judiciario/direitocoletivo $>$. Acesso em: 25 de janeiro de 2017.

23 BRASIL, Op. Cit. p 43. 
Com relação ao já transcrito artigo $5^{\circ}$ inciso LXX da Constituição da República de 1988 se faz necessário buscar a maior definição da norma dentro do ordenamento jurídico. Desse modo, o inciso não pode ser considerado taxativo e suprimir a possibilidade de impetração do mandado de injunção pelo Ministério Público com o escopo de defender direitos difusos e coletivos.

Ademais, conforme estabelece Alessandra Mendes Spalding:

[...] afigura-se que o Ministério Público é parte legítima para impetrar o mandado de segurança coletivo, pois o texto constitucional, quando lhe incumbiu a defesa dos interesses sociais e individuais indisponíveis (art. 127, caput) e lhe atribuiu, entre as suas funções institucionais, a proteção do patrimônio público e social, meio ambiente e outros interesses difusos e coletivos, concedeu-o legitimidade para ajuizar as ações previstas em nosso ordenamento jurídico, dentre elas a ação coletiva fundamental ${ }^{24}$

Sendo assim, o Ministério Público figura como parte legítima na impetração do mandado de segurança coletivo quando se tratar de direito individual indisponível, além dos direitos difusos e coletivos.

A norma do inciso LXX do artigo $5^{\circ}$ da Carta Fundamental de 1988 não estabelece, no plano gramatical, qualquer restrição a possibilidade de outros legitimados para impetração do mandado de segurança coletivo. Observa-se, portanto, que o Ministério Público figura como legitimado, porém, em dispositivo diverso (artigo 127, caput da Constituição Federal de 1988).

Entre as já citadas funções primordiais do Ministério Público destaca-se a defesa dos interesses sociais e individuais indisponíveis. Desse modo, não pode o parquet ter uma das formas de defesa dos referidos direitos cerceada. Por essa razão deve ser parte legítima na utilização de todos os instrumentos que possam tutelar direitos indisponíveis, sociais, coletivos e difusos. O argumento de que o Ministério dispõe de outros meios para garantir o exercício em juízo se mostra superficial e sem utilidade, uma vez que cada instrumento processual disponível é único e existe para a plena e efetiva tutela jurisdicional, mesmo que haja outros instrumentos hábeis, mesmo que de forma parcial, para tal feito.

\section{CONSIDERAÇÕES FINAIS}

Constata-se, ao longo do presente estudo, que o Ministério Público, mesmo não sendo parte constante no inciso LXX do artigo $5^{\circ}$ da Constituição Federal de 1988, deve ser conhecido como legitimado para impetrar o mandado de segurança coletivo quando se tratar de direito coletivo, difuso ou individual indisponível. A legitimidade do parquetem impetrar o mandado de segurança coletivo consta nos artigos 127 e 129 da Constituição Federal, visto que o Ministério Público tem por dever proteger os interesses sociais, individuais indisponíveis, coletivos e difusos e por essa razão não pode ser afastada a possibilidade de ser parte legítima em impetrar o mandado 
de segurança coletivo quando se tratar dos referidos direitos. Não há que olvidar o fato de que mesmo havendo outros instrumentos a disposição do parquet, o mandado de segurança coletivo apresenta suas características e qualidades ímpar e por isso, negar a legitimação não permite ao Ministério Público exercer as suas atribuições de forma plena e eficaz e garantir a proteção da sociedade.

\section{REFERÊNCIAS BIBLIOGRÁFICAS}

SPAlDING, Alessandra Mendes. A Legitimidade Ativa na Ação Popular na Ação Civil Pública e no Mandado de Segurança Coletivo. Londrina. 2003. Dissertação (Mestrado em Direito Negocial) - Universidade Estadual de Londrina, Londrina.

BRASIL, Constituição da República dos Estados Unidos do Brasil (De 16 de julho de 1934). Disponível em:

$<$ http://www.planalto.gov.br/ccivil_03/constituicao/constituicao34.htm $>$ Acesso em 10 de agosto de 2017.

SILVA, José Afonso da. Curso de Direito Constitucional Positivo. $11^{\circ}$ ed. São Paulo: Malheiros. 1996.

BRASIL, Constituição da República Federativa do Brasil: texto promulgado em 5 de outubro de 1988, com as alterações adotadas pelas Emendas constitucionais n ${ }^{\circ}$ 1/1992 a 77/201, 41 ed. Brasília: Câmara dos Deputados, Edições Câmara, 2014.

MARTINS, Ives Gandra da Silva. Conheça a Constituição: Comentários à Constituição Brasileira, volume 1. Barueri-SP: Manole, 2005.

MEIRELLES, Hely Lopes. Mandado de Segurança. 29 ed. São Paulo: Malheiros, 2006, p. 21-22 BRASIL, Lei $\mathbf{n}^{\mathbf{0}}$ 12.016 de 07 de agosto de 2009. Disponível em: <http://www.planalto.gov.br/ ccivil_03/_ato2007-2010/2009/lei/112016.htm> Acesso em: 29 de janeiro de 2017

BRASIL, Superior Tribunal de Justiça, Recurso em Mandado de Segurança - RMS 49.020/ SP.Recorrente: Caixa Econômica Federal. Recorrido:Katal Biotecnologia Indústria e Comércio LTDA.Rel. Ministro RAUL ARAÚJO, QUARTA TURMA, julgado em 10/11/2015, DJe $26 / 11 / 2015$

ALVIM, Eduardo Arruda. Direito Processual Civil. 2a Edição. São Paulo: Editora Revista dos Tribunais, 2008.

DANTAS, Marcelo Navarro Ribeiro, Mandado de Segurança Coletivo: legitimação ativa. São Paulo: Saraiva, 2000

BRASIL, Tribunal de Justiça do Rio Grande do Sul8 ${ }^{a}$ Câmara Civil- Mandado de Segurança: 70049089212 RS, Impetrante: Defensoria Pública. Coator: E.P.J.C.P.M., P.M.P.M. Relator: Ricardo Moreira Lins Pastl, Data de Julgamento: 23/08/2012. Data de Publicação: Diário da Justiça do dia 28/08/2012. 
BRASIL, Tribunal de Justiça do Riode Janeiro, $5^{\text {a }}$ Câmara Cível.Apelação: 00393071720048190001. Apelante: Ministério Público. Apelado: Estado do Rio de Janeiro Relator: MILTON FERNANDES

DE SOUZA, Data de Julgamento: 20/06/2006. Data de Publicação: 26/06/2006.

BRASIL, Superior Tribunal de Justiça - Primeira Turma- Recurso Especial: 806304 RS 2005/0212409-1,Recorrente: Ministério Público Federal, Tim Celular S/A e BCP S/A. Recorrido: União, Agência Nacional de Telecomunicações ANATEL e Companhia Rio-grandense de Telecomunicações CRT. Relator: Ministro LUIZ FUX, Data de Julgamento: 02/12/2008. Data de Publicação: DJe 17/12/2008.

BRASIL. Código de Defesa do Consumidor (1990). In: ANGHER, Anne Joyce. VadeMecum acadêmico de Direito RIDEEL. 18. ed. São Paulo: RIDEEL, 2014.

TRIBUNAL DE JUSTIÇA DO DISTRITO FEDERAL E DOS TERRITÓRIOS. Direito Coletivo. Disponível: $<$ http://www.tjdft.jus.br/acesso-rapido/informacoes/vocabulario-juridico/entendendoo-judiciario/direito-coletivo> Acesso em: 25 de janeiro de 2017.

Como citar: BARON, José Ricado da Silva. ESTEVES, João Luis Martins. A legitimidade do ministério público para impetrar o mandado de segurança coletivo na proteção dos direitos difusos, coletivos e individuais indisponíveis à luz da legislação brasileira. Revista do Instituto de Direito Constitucional e Cidadania, Londrina, v. 3, n. 2, p. 136-150, jul/dez. 2018. 